\title{
IDENTIFICATION OF ANTHRACHNOSE DISEASE ON STRAWBERRY FRUIT (Fragraria vesca L.) AND ITS CONTROL BY BETEL (Piper betle L.) LEAF EXTRACT
}

\author{
Rina Sri Kasiamdari and Umi Sangadah \\ Faculty of Biology, Universitas Gadjah Mada, \\ Jl. Tekhnika Selatan, Sekip Utara Yogyakarta 55281
}

\begin{abstract}
In Indonesia, strawberry is one of fruits which has high economic values. The growth of strawberry has increased significantly, but its productivity is still low because of disease attack. Disease that attacks strawberry started from nursery to post harvest is anthracnose that can be caused by Colletotrichum spp. Control efforts of anthracnose disease up to now has been done with application of synthetic chemicals which are known to be hazardous to the environment and human health. Betel leaf (Piper betle L.) is natural plant that potentially used as phytofungicide. Essential oils on betel leaf extract is reported can decrease the growth of pathogenic fungi. The objectives of the research were to identify Colletotrichum spp. in strawberry fruit that showed anthracnose symptoms, to test the potency of betel leaf extract as phytofungicide, and to evaluate the effect of betel leaf extract in inhibiting infection and disease severity of Colletotrichum in strawberry. Samples were taken from strawberry nursery in Magelang, Indonesia. The disease symptoms were isolated on Potato Dextrose Agar, followed by identification of fungal colony and morphology by semi permanent slide preparation. Betel leaves were extracted with water to get a concentration of 20, 40, 60, 80 and 100\%, respectively. An in vitro experiment was done to evaluate the inhibition rate of betel leaf extract to the growth of Colletotrichum spp. colony. An in vivo experiment was done by submersion of strawberry to betel leaf extract before (preventive method) and after antrachnose attack (curative method), then disease infection and disease severity were measured after 7 days. The result of the research showed that anthracnose disease in strawberry was caused by $C$. gloeosporioides (Penz.). Twenty percent of betel leaf extract in an in vitro test had potential as phytofungicide and concentration of $100 \%$ betel leaf extract was the best concentration to inhibit the growth of $C$. gloeosporioides (Penz.) colony by $70.26 \pm 0,61 \%$. In an in vivo experiment, submersion of strawberry before pathogen infection (preventive) with $100 \%$ betel leaf extract decreased disease infection by $40 \%$ and disease severity by $16 \%$, respectively. While treatment of submersion of strawberry after pathogen infection (curative) decreased disease infection by $33,4 \%$ and disease severity by $17 \%$.
\end{abstract}

Key words: strawberry, anthrachnose, disease, betel leaf

\section{INTRODUCTION}

In Indonesia, strawberry is a fruit of high economic value due to market demand continues to rise. According to the Central Bureau of Statistics (2011), strawberry production in Indonesia in 2009 amounted to 19.132 tons in 2010 and has developed production by $29.87 \%$ to total production in 2010 is 24.846 tons. Strawberries productivity in Indonesia is still low compared to other developing countries. One obstacle in the development of strawberry production in Indonesia is unfavorable climate, precise method of cultivation, low productivity, and the presence of pests and diseases. Such constraints result in low productivity levels.

Pests and diseases that attack strawberry plants can result in decreased production that can even lead to death of the plants. Diseases that attack strawberries include anthracnose disease caused by Colletotrichum fragariae Brooks, C. acutatum Simmonds, and C. gloeosporioides (Penz.) (Mertely et al., 2007). Colletotrichum spp. cause economically significant diseases such as wilt disease, rot, and anthracnose in strawberry production areas. In the Zhejiang region reported that nearly $50 \%$ of deaths occurred at the time of seeding and more than $40 \%$ yield losses in strawberry production fields caused by anthra-

ISSN 2413-0877 @ 2015 The Authors.

Published by KnowledgeE Publishing Services This is an open access article under the CC BY-NC-ND license (http://creativecommons.org/licenses/by-nc-nd/4.0) 
cnose. In China for many years, the strawberry production area was affected by the disease (Xie et al., 2010). Management of this disease is greatly hindered by the difficulty in detection and control of this fungus during symptomless infections on strawberry leaves and unripe fruit (Debode et al. 2009; Van Hemelrijck et al. 2010; Guidarelli et al. 2011).

Currently, the control of fungal diseases of strawberry relies mainly on the use of fungicides. Efforts to control anthracnose disease undertaken to date are by the application of synthetic fungicides both systemic and non-systemic fungicides for practical, easy to obtain, easy to use, and shows a rapid effect. Generally, anthrachnose diseases can be controlled by a wide range of chemicals such as copper compounds, dithiocarbamates, benzimidazole and trizole compounds; other fungicides such as chlorothalonil, imazalil and prochloraz are also effective against Colletotrichum (Waller, 1992). The synthetic fungicides often leave residues which are harmful to the environment and human health if consumed. This is because the synthetic fungicide on fruit difficult to decompose and become residues in the human body (Debode et al., 2013).

Biological control of strawberry fungal diseases using plant extract has been proposed as a promising alternative control strategies to reduce dependency on synthetic fungicides. Plants contain thousands of constituents and are valuable sources of new and biologically active molecules possessing antimicrobial property. Use of natural plant extracts provides an opportunity to avoid chemical preservatives. Antifungal action of plant extracts has great potential as they are easy to prepare and apply. Further, these are safe and effective in view of their systemic action and lack residual effect, easily biodegradable and exhibit stimulating effect on plant metabolism. Large number of earlier workers has reported antifungal properties of several plant species (Kubo et al., 1995). One of them is the betel vine plant (Piper betle L.) which is a perennial dioecious, semi woody climber with heart-shaped leaves belongs to the family Piperaceae. It is cultivated widely in southeastern Asian countries and used variously for both traditional and medicinal practice. The leaves contain essential oils including chavicol, chavibitol eugenol, carvacrol, aryophyllene and sitosterol, which possess anti fungal properties (Srichana et al., 2009). P. betle is a medicinally important plant and well studied for antimicrobial activity but poorly explored to screen antifungal potency against various plant disease causing fungal strains. The objectives of the research were to identify Colletotrichum spp. in strawberry fruit that showed anthracnose symptoms, to test the potency of betel leaf extract as phytofungicide, and to evaluate the effect of betel leaf extract in inhibiting infection and disease severity of Colletotrichum in strawberry.

\section{MATERIALS AND METHODS}

\section{Fungal Isolate and Identification}

Isolation was done by cutting the fruit tissue which showed disease symptom with the size of $0.5 \times 0.5\left(\mathrm{~cm}^{2}\right)$. Tissues were submersed on $1 \% \mathrm{NaCl}$ for 1 minute, rinsed with sterile distilled water for 1 minute, then wind dried on sterile filter paper and grown on Potato Dextrose Agar (PDA) medium and incubated at room temperature for 7 days. Identification was done by making semi permanent slides using tryphan blue dye. Microscopic observation of Colletotrichum spp. included the shape and size of conidia, hyphae, shape and size of the seta. Images are matched with fungal identification books of Gandjar et al. (1999). 


\section{Betel leaf extract}

Betel leaf was weighed 100 grams, washed with water, cut into pieces, blended by adding $100 \mathrm{ml}$ of distilled water, and then filtered. Concentration of the crude aqueous extract obtained was considered $100 \%$. The different dilutions of extract $(20,40,60$ and 80 \%) from initial concentration was made.

\section{Antifungal activity of $\boldsymbol{P}$. bettle aqueous extract in vitro}

In vitro experiment was done In vitro testing was done by mixing $2 \mathrm{ml}$ of betel leaf extract of each concentrations ( $20 \%, 40 \%, 60 \%, 80 \%, 100 \%)$ with $10 \mathrm{ml}$ PDA and pouring it into petri dishes. Pure cultures of Colletotrichum was then placed on the petri dishes and incubated at room temperature until the colony reached the edge of the petri dishes. Positive control was done by application of $0.2 \%$ Dithane fungicide $2 \mathrm{ml}$ on to the PDA (Marhaenis, 2011), whereas negative control used PDA with addition of $2 \mathrm{ml}$ sterile distilled water. Growth inhibition was measured as follows: $\varnothing \mathrm{C}-\varnothing \mathrm{T} / \varnothing \mathrm{C} \times 100 \%$, where $\varnothing \mathrm{C}$ is the colony diameter of control $(\mathrm{cm}), \varnothing \mathrm{T}=$ the diameter colony of treatment $(\mathrm{cm})$.

\section{Antifungal activity of $P$. bettle aqueous extract in vivo}

a. Preventive method

Strawberries were sterilized using $70 \%$ alcohol and then dried. Strawberries were then submersed in a selected betel leaf extract for 10 minutes and then dried. Negative control was done by submersion with sterile distilled water, while positive control was done by submersion of $0.2 \%$ Dithane fungicide. Fruits were incubated for 1 day and then inoculated with Colletotrichum by injecting at a depth of $1 \mathrm{~mm} 0.1 \mathrm{ml}$ suspension of $10^{6}$ conidia of Colletotrichum at 10 different places. Inoculated fruits were then covered with transparent plastic and incubated at room temperature until the anthracnose symptoms appeared. Each treatments were replicated 15 times. Observations were made every day for 7 days after the onset of symptoms by counting anthracnose infection and disease intensity .

\section{b. Curative method}

Strawberries were sterilized using $70 \%$ alcohol and then dried. Inoculation was done by injecting at a depth of $1 \mathrm{~mm} 0.1 \mathrm{ml}$ suspension of $10^{6}$ conidia of Colletotrichum at 10 different places. Inoculated fruits were then covered with transparent plastic and incubated at room temperature until the anthracnose symptoms appeared. Once symptoms appeared, strawberries were submersed in a selected betel leaf extract for 10 minutes and then dried. Negative control was done by submersion with sterile distilled water, while positive control was done by submersion of $0.2 \%$ Dithane fungicide. Each treatments were replicated 15 times. Observations were made every day for 7 days after the onset of symptoms by counting anthracnose infection and disease intensity.

\section{Measurements of disease infection and disease severity of anthracnose}

Disease infection was measured by the formula of $\mathrm{DI}=\mathrm{n} / \mathrm{N} \times 100 \%$, where $\mathrm{DI}=$ disease infection, $\mathrm{n}=$ number of fruits showing symptoms of anthracnose, $\mathrm{N}=$ number of fruits observed in each treatments. 
Disease severity was measured by the formula of DS $=\Sigma(n \times V) / Z \times N \times 100 \%$, where DS $=$ Disease severity, $n=$ number of fruits in the same category at each attack, $V=$ score of each category of attack, $\mathrm{N}=$ number of fruits observed, $\mathrm{Z}$ = highest score attack.

The disease score was measured as follows: $0=$ There was no attack, $1=0<x<20 \%$ of the fruit was attacked, $2=20<x<40 \%$ of the fruit was attacked, $3=40<x<60 \%$ of the fruit was attacked, $4=60<x<80 \%$ of the fruit was attacked, $5=80<x<100 \%$ of the fruit was attacked

\section{Data analysis}

In vitro and in vivo experiments were done using CRD (completely randomized design). Data were analysed by ANOVA. If the results are significantly different from the median value comparisons were made between treatments by Duncan's test at the significance level $(\alpha)=5 \%$.

\section{RESULTS AND DISCUSSION}

\section{Fungal isolation and identification}

Collected strawberry fruit showed symptoms of brown spots, mushy, then spotting turned into a dark brown or black (Fig. 1A). These spots coalesce to form large patches. The spotted fruit isolated on the PDA showed colonies varied, and after identification based on colony morphology and microscopic discovered several types of fungi including Rhizoctonia, Fusarium, Aspergillus and Colletotrichum (data not shown). Colletotrichum colonies were then made into pure cultures and identified further. Microscopic identification results showed that the colony was white to pink and dark gray, conidia were aseptate, hyaline and one-celled, oval shape with a blunt edge with length of $10.1 \mathrm{um} \times 4.02 \mathrm{um}$ (Fig. 1C), hyphae was hyaline and septated (Fig 1B), seta was straight, dark brown, with the size of 62-112 um (Fig 1D). The results showed similarity with the reference identification of Lubbe et al. (2004) and Xie et al. (2010) and identified as Colletotrichum gloeosporioides (Penz.)

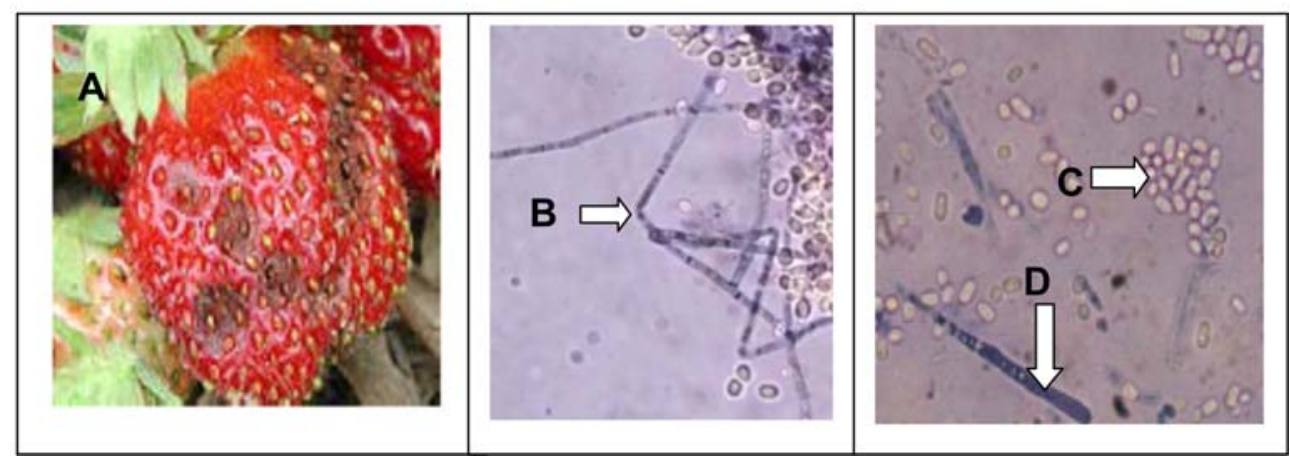

Figure 1. Anthrachnose disease on strawberry (A), hyphae (B), conidia (C) and seta (D) of Coletotrichum gloeosporioides (Penz.) 


\section{Antifungal activity of $\boldsymbol{P}$. bettle aqueous extract in vitro}

In vitro test was conducted by measuring the growth of $C$. gloeosporioides colony diameter on PDA every day until the colony filled petri dish. The percentage of inhibition was calculated to determine the inhibitory concentration of betel leaf extract ( $100 \%, 80 \%, 60 \%$ , $40 \%, 20 \%$ ) and positive control (0.2\% Dithane) on the growth of C. gloeosporioides colony diameter. Figure 1 showed that from day 1 to day 5 it showed that greater concentration of betel leaf extract showed greater percentage of $C$. gloeosporioides inhibition. On the day 5 , it showed that the percentage of inhibition of Betel leaf extract (BLE) against $C$. gloeosporioides was between $32.13 \%$ to $70.26 \%$, while the positive control $(0.2 \%$ Dithane) was $55.4 \%$. Betel leaf extract $80 \%$ and $100 \%$ had higher inhibition than the positive control. The use of $100 \%$ BLE showed the highest inhibition or most effective in inhibiting the growth of $C$. gloeosporioides.

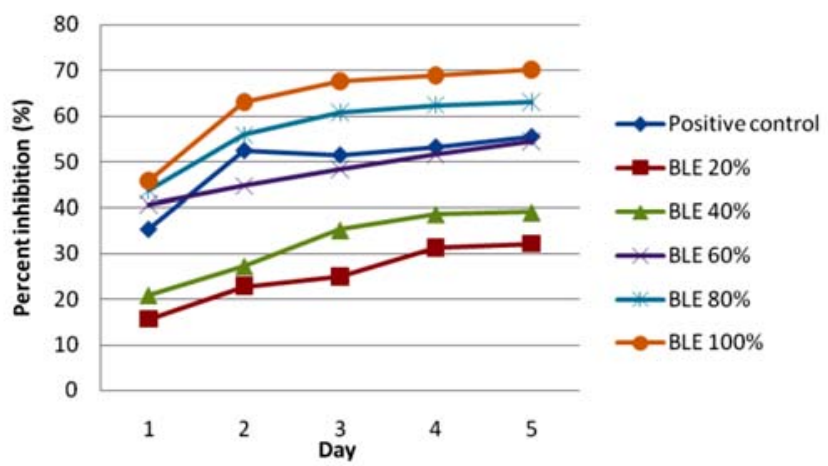

Figure 2. Percent inhibition of Betel leaf extract (BLE) at the concentration of 20, 40,60,80, and $100 \%$ and positive control (Dithane fungicide) to Colletotrichum gloeosporoides (Penz.).

Jesonbabu et al., (2012) stated that betel leaf has a significant antimicrobial activity against broad spectrum of micro-organisms, including fungi. A major phenolic compound called hydroxychavicol from aqueous extract of the $P$. betle leaves, was reported to have antimicrobial activity, antioxidant and anticancer properties in several studies conducted by various researchers (Chang et al., 2002; Ramji et al., 2002; Sharma et al., 2009). It has also been reported that $P$.betle is rich in chemical constituents such as campene, carvacrol, methyl chavibetol, eugenol, limonene, pinene, safrole and 1,8-cineole (Rimando, 1986). Among these, the common terpene compounds such as carvacrol, linalool and eugenol have been known to exhibit antifungal activity towards several strains of microorganisms. In addition, there are many secondary metabolites and chemical constituents produced in $P$. betle extracts that may contribute to the observed positive antifungal effects (Kim et al., 1995).

\section{Antifungal activity of $P$. bettle aqueous extract in vivo}

a. Disease infection

Based on the preventive test results by performing fruit soaking before strawberry disease appears, it was known that control plants demonstrated disease after 3 days of inoculation with C.gloeosporoides, whereas treatments with Dithane and BLE did not shown symptoms of the disease. On day 7 after inoculation seen that BLE $100 \%$ could reduce infections by $40 \%$, whereas Dithane only reduced infection by $33.4 \%$ (Table 1 ). Meanwhile, the curative method showed no significant difference from day 3 to day 6 , whereas on day 7 of 
infection diseases with treatment BLE $100 \%$ at $53.3 \%$, this value was lower compared with Dithane treatment and control. With curative method, at day 7, BLE $100 \%$ capable of reducing infection by $33.4 \%$, while $26.7 \%$ of Dithane (Table 2). Report by Johnny et al. (2011) showed that leaf crude extracts of P.betle exhibited the highest antifungal activities overall in inhibiting the mycelial growth of $C$. capsici among the 15 medicinal plants. This research showed $P$. betle leaf crude extract of $10.00 \mathrm{ig} / \mathrm{ml}$ exhibited the highest percent of inhibition against $C$. capsici between 72.91 and $80.93 \%$, respectively. The differences on the results might be caused by different extracts used in the study.

Table 1. Reduction of anthrachnose disease infection on strawberry by preventive method

\begin{tabular}{|c|c|c|c|c|c|}
\hline \multirow[b]{2}{*}{ Treatment } & \multicolumn{5}{|c|}{ Disease Infection (\%) } \\
\hline & Day 3 & Day 4 & Day 5 & Day 6 & Day 7 \\
\hline Negative Control & $26.7 \pm 11.6 \mathrm{~b}$ & $40.0 \pm 20.0 \mathrm{~b}$ & $66.7 \pm 23.1 \mathrm{~b}$ & $73.3 \pm 11.6 \mathrm{~b}$ & $86.7 \pm 11.6 b$ \\
\hline $\begin{array}{l}\text { Betel leaf Extract } \\
\text { (BLE) } 100 \%\end{array}$ & $0 \pm 0 \mathrm{a}$ & $0 \pm 0 \mathrm{a}$ & $26.7 \pm 11.6 \mathrm{a}$ & $40.0 \pm 0 \mathrm{a}$ & $46.7 \pm 11.6$ a \\
\hline $\begin{array}{l}\text { Positive Control } \\
0.2 \% \text { Dithane) }\end{array}$ & $0 \pm 0$ a & $6.7 \pm 11.6 \mathrm{a}$ & $33.3 \pm 11.6 \mathrm{a}$ & $53.3 \pm 11.6 \mathrm{a}$ & $53.3 \pm 11.6 \mathrm{ab}$ \\
\hline
\end{tabular}

Table 2. Reduction of anthrachnose disease infection on strawberry by curative method

\begin{tabular}{llllll}
\hline & \multicolumn{5}{c}{ Disease Infection (\%) } \\
\cline { 2 - 6 } Treatments & \multicolumn{1}{c}{ Day 3 } & Day 4 & Day 5 & Day 6 & Day 7 \\
\hline Negative Control & $20.0 \pm 0$ a & $40.0 \pm 0$ a & $60.0 \pm 20.0$ a & $73.3 \pm 11.6$ a & $86.7 \pm 11.6 \mathrm{~b}$ \\
$\begin{array}{l}\text { Betel Leaf Extract } \\
\text { (BLE) 100\% }\end{array}$ & $20.0 \pm 0$ a & $46.7 \pm 11.6$ a & $53.3 \pm 11.6$ a & $53.3 \pm 11.6$ a & $53.3 \pm 11.6$ a \\
$\begin{array}{l}\text { Positive Control } \\
(0.2 \% \text { Dithane) }\end{array}$ & $26.7 \pm 11.5$ a & $46.7 \pm 11.6$ a & $53.3 \pm 11.6$ a & $53.3 \pm 11.6$ a & $60.0 \pm 20.0$ ab \\
$\begin{array}{l}\text { Values in the same column followed by the same letter were not significantly different } \\
(\alpha=5 \%)\end{array}$
\end{tabular}

\section{b. Disease severity}

Results of studies using preventive methods showed that disease severity was generally higher in the control treatment than in the treatment of BLE $100 \%$ or Dithane, this suggests that the use of BLE $100 \%$ can reduce disease severity on fruit strawbery (Table 3). For treatment with curative method in which the application of BLE $100 \%$ was done after fruit disease, showed that the BLE effectively inhibited disease severity on day 6 with disease severity $14.6 \%$ lower than controls, and on day 7 , it was significantly effective in reducing disease severity up to $17 \%$. BLE $100 \%$ treatment was not significantly different despite significantly lower values of its severity disease than Dithane (Table 4).

Similar study by Amadioha (1999) showed that water extracts of $P$. bettle and other plant extracts of Ocimum sanctum and Citrus limon were effective against Colletotrichum lindemuthianum the incidence and spread of the disease caused by the pathogen in the field. Extracts of $P$. betlewas the best in reducing the growth of the pathogen in culture and in checking the spread of anthracnose disease of cowpea in the field. Based on the above data indicate that the use of BLE $100 \%$ despite significantly reduced disease severity of infection and disease, would not be significantly different from the use of Dithane. Nevertheless, in terms of safety, BLE $100 \%$ can be recommended as a biocontrol of anthrachnose disease on strawberry fruit, because it contains no chemicals that are harmful to health and the use of BLE is not harmful to the environment. 
Table 3. Disease severity on strawberry inoculated with Colletotrichum gloeosporioides (Penz.) by preventive method

\begin{tabular}{|c|c|c|c|c|c|}
\hline \multirow[b]{2}{*}{ Treatments } & \multicolumn{5}{|c|}{ Disease Severity (\%) } \\
\hline & Day 3 & Day 4 & Day 5 & Day 6 & Day 7 \\
\hline Negative Control & $5.3 \pm 2.3 \mathrm{~b}$ & $12.0 \pm 8.0 \mathrm{~b}$ & $28.0 \pm 6.9 \mathrm{~b}$ & $34.7 \pm 2.3 \mathrm{a}$ & $46.7 \pm 6.1 \mathrm{~b}$ \\
\hline $\begin{array}{l}\text { Betel leaf extract } \\
\text { (BLE) } 100 \%\end{array}$ & $0 \pm 0 \mathrm{a}$ & $0 \pm 0 \mathrm{a}$ & $8.0 \pm 4.0 \mathrm{a}$ & $20.0 \pm 8.0 \mathrm{a}$ & $30.7 \pm 8.3 a$ \\
\hline $\begin{array}{l}\text { PositiveControl } \\
\text { (0.2\% Dithane) }\end{array}$ & $0 \pm 0 \mathrm{a}$ & $1.3 \pm 2.3 \mathrm{a}$ & $9.3 \pm 4.6 \mathrm{a}$ & $21.3 \pm 10.1 \mathrm{a}$ & $32.0 \pm 8.0 \mathrm{ab}$ \\
\hline
\end{tabular}

Table 4. Disease severity on strawberry inoculated with Colletotrichum gloeosporioides (Penz.) by curative method

\begin{tabular}{lccccc}
\hline & \multicolumn{5}{c}{ Disease Severity (\%) } \\
\cline { 2 - 6 } Treatments & Day 3 & Day 4 & Day 5 & Day 6 & Day 7 \\
\hline Negative Control & $4.0 \pm 0$ a & $12.0 \pm 0$ a & $24.0 \pm 4.0$ a & $37.3 \pm 4.6 \mathrm{~b}$ & $46.3 \pm 8.3 \mathrm{~b}$ \\
Betel Leaf Extract & $4.0 \pm 0$ a & $12.0 \pm 4.0$ a & $18.7 \pm 2.3$ a & $22.7 \pm 6.1$ a & $29.3 \pm 6.1$ a \\
(BLE) $100 \%$ & & & & \\
PositiveControl & $5.3 \pm 2.3$ a & $12.0 \pm 0$ a & $20.0 \pm 6.9$ a & $26.7 \pm 6.1$ ab & $33.3 \pm 10.1 \mathrm{ab}$ \\
\hline $\begin{array}{l}\text { Values in t he same column followed by the same letter were not significantly different } \\
(\alpha=5 \%)\end{array}$
\end{tabular}

\section{CONCLUSIONS}

Anthracnose disease in strawberry was caused by C. gloeosporioides (Penz.). Twenty percent of betel leaf extract in an in vitro test had potential as phytofungicide and concentration of $100 \%$ betel leaf extract was the best concentration to inhibit the growth of $C$. gloeosporioides (Penz.) colony by $70.26 \pm 0,61 \%$. In an in vivo experiment, submersion of strawberry before pathogen infection (preventive) with $100 \%$ betel leaf extract decreased disease infection by $40 \%$ and disease severity by $16 \%$, respectively. While treatment of submersion of strawberry after pathogen infection (curative) decreased disease infection by $33,4 \%$ and disease severity by $17 \%$.

\section{REFERENCES}

Camadioha, A. 1999. Evaluation of some plant leaf extracts against Colletotrichum lindemuthianum in cowpea. Arch.Phytopath.Pflanz, 32: 141-149.

Central Bureau of Statistics. 2011. Several developments Main Socio-Economic Indicators of Indonesia. http://www.bps.go.id, accessed 11 November 2012.

Chang, M.C., B.J. Uang, H.L. Wu, J.J. Lee, and J.H. Jeng. 2002. A major phenolic compound in Piper betle leaves. Br. J. Pharmacol. 135: 619-630.

Dasgupta, N., and B. De. 2004. Antioxidant activity of Piper betle L. leaf extract in vitro. Food Chem., 88: 219-224.

Debode J., W. Baeyen, S. Van Hemelrijck, P. Creemers, K. Heungens, and M. Maes. 2009. Quantitative detection and monitoring of Colletotrichum acutatum in strawberry leaves using real-time PCR. Plant. Pathol. 58:504-514.

Debode J., W. Van Hemelrijck, P. Creemers, and M. Maes. 2013. Effect of fungicides on epiphytic yeasts associated with strawberry. Microbiology open, 2 (3): 482-491.

Gandjar I., W. Sjamsuridzal, and A. Oetari. 2006. Basic and Applied Mycology. Yayasan Obor Indonesia. Jakarta, pp. 3-4. 
Guidarelli M., F. Carbone, F. Mourgues, G. Perrotta, C. Rosati, and P. Bertolini. 2011. Colletotrichum acutatum interactions with unripe and ripe strawberry fruits and differential responses at histological and transcriptional levels. Plant. Pathol., 60:685-697.

Jesonbabu, J., N. Spandana, and K.A. Lakshmi. 2012. In vitro antimicrobial potentialities of chloroform extracts of Ethanomedicinal plant against clinically isolated human pathogens. Int. J. Pharm. Pharm. Sci. 4 (3): 624-626.

Johnny, L., U.Y. Yusuf, and R. Nulit. 2011. Antifungal activity of selected plant leaves crude extracts against a pepper anthracnose fungus, Colletotrichum capsici (Sydow) butler and bisby (Ascomycota: Phyllachorales). African Journal of Biotechnology, 10 (20): 4157-4165

Kim, J., M.R. Marshall, and C. Wei. 1995. Antibacterial activity of some essential oil component against five foodborne pathogens. J. Agric Food Chem., 43 (11): 28392845.

Kubo, A., C.S. Lunde, and I. Kubo. 1995. Antimicrobial activity of the olive oil flavor compounds. Journal of Agricultural. Food Chemistry. 43: 1629-1633.

Lubbe, C. M., S. Denman, P.F. Cannon, J.Z. Groenewald, and P.W. Crous. 2004. Characterization of Colletotrichum species associated with diseases of Proteaceae. Mycologia 96 (6):1273.

Marhaenis, E. 2011. Potential of Watercress Extract (lpomea aquatica Forsk.) As Biofungisida for Disease Control of Fusarium Fruit Rot in Tomato Fruit. Thesis. Faculty of Agriculture. Bogor Agricultural Institute.

Mertely, J.C., N.A. Peres, and C.K. Chandler. 2007. Anthracnose Fruit Rot of Strawberry. http://edis.ifas.ufl.edupdffilesPPPP13000.pdf, accessed 2 Mei 2012.

Ramji, N., R. lyer, and S. Chandrasekaran. 2002. Phenolic antibacterials from Piper betle in the prevention of halitosis. J.Ethnopharm., 83: 149-152.

Rimando, A.M. 1986. Studies on the constituents of Philippines P.betle leaves. Arch. Pharmacol. Res., 9: 93-97.

Sharma, S., I. Ali Khan, I. Ali, F. Ali, M. Kumar, A. Kumar, R.K. Johri, S.T. Abdullah, S. Bani, A. Pandey, K.A. Suri, B.D. Gupta, N.K. Satti, P. Dutt, and G.N. Qazi. 2009. Evaluation of the antimicrobial, antioxidant and antiinflammatory activities of hydroxychavicol for its potential use as an oral care agent. Antimicrob. Agents Chemother., 53 (1):216-222.

Srichana, D., A. Phumruang, and B. Chongkid. 2009. Inhibition effect of betel leaf extract on the growth of Aspergillus flavus and Fusarium verticillioides. Thammasat Int. J. Sc. Tech, 14 (3): 74-77. 